\title{
Synthesis and Evaluation of New Environment- Friendly Starch Hydroxypropyl Phosphate as Flocculant
}

\author{
A. Hebeish, Amal A. Aly and S. Farag \\ Textile Research Division, National Research Center, Cairo, \\ Egypt.
}

\begin{abstract}
Dhosphate adduct, namely, 2-hydroxy-3-chloropropylphosphate was reacted with starch in presence of sodium hydroxide catalyst according to the dry process to yield starch hydroxypropyl phosphate. The reaction was conducted under a variety of conditions and the extent of reaction expressed as DS (degree of substitution), was found to rely on catalyst concentration and phosphate adduct concentration as well as duration and temperature of the reaction. In this way starch molecules bearing different amounts of hydroxypropyl phosphate groups could be achieved. Evaluation of these starch hydroxypropyl phosphates as flocculant for ferric laurate and kaolin was performed under different conditions including dose, phosphorus content, $\mathrm{pH}$ of the flocculation and molar mass. The results obtained advocate the namely synthesized starch hydroxypropyl phosphates as a good candidate for flocculation vis-à-vis the well known poly(acrylamideco-acrylic acid) which is used as industrial flocculant.
\end{abstract}

Keywords: Flocculation, Ferric laurate, Kaolin, Poly(acrylamide-coacrylic acid) and Starch hydroxpropyl phosphate.

Polymer-based flocculants find application in a number of industrial processes to precipitate suspended solids from wastewater before disposal or recycling ${ }^{(1)}$. They are also used to reduce soil erosion in irrigated agriculture by binding together soil particles ${ }^{(2)}$. Such polymers are characterized by high molecular weight and have positive and/or negatively charged groups in order to bind to the polar surfaces of suspended particles ${ }^{(1,3)}$. These anionic flocculants are very useful for sedimentation of copper flotation tailing, fine clay particles, waste water of porcelain manufacture, phosphatic clay waste, selective flocculation for dolomite-apatite system $^{(4)}$, smectite, illite, kaolinite ${ }^{(5)}$, cement fluid loss polymer $^{(6)}$, fine particles in ceramic wastewater ${ }^{(7)}$, and turbidity removal from wastewaters of natural stone processing ${ }^{(8)}$.

In common practice, the said polymers include polyacrylamide, copolymerization of acrylamide with comonomers bearing acidic groups ${ }^{(9)}$, polyacrylic acid, or from ( $\mathrm{N} \alpha-$ Boc- $\mathrm{N} \varepsilon$-acrolyl-1-lysylglycine methyl ester) via radical polymerization, poly(acrylamide-co-acrylic acid) ${ }^{(10,11)}$, and various cationics. However, these polymers suffer from certain drawbacks, including, increasing costs of petroleum feed stocks, very slow biodegradation in soil and 
water and toxicity of residual monomer which is usually present in small amounts. This has evoked special interest in disablement of flocculants which are based on biopolymers.

Indeed, there has been increasing interest recently in developing new biobased, biodegradable flocculants such as guar gum, alginate ${ }^{(12)}$, dextrins ${ }^{(13)}$, modified starches $^{(4)}$, celluloses ${ }^{(3)}$ and bacterial polysaccharides ${ }^{(14)}$. A series of phosphatemodified Konjac was synthesized by esterification of natural polysaccharide Konjac $^{(15)}$. Chemically modified starches such as starch graft copolymers, cationic starches $^{(16-18)}$, starch xanthates ${ }^{(2)}$, carboxymethyl starches ${ }^{(19)}$, have been prepared. The carboxymethylation has been done via reacting starch with monochloroacitic acid, saponification of polyacrylonitrile-starch graft copolymer, polyacrlyamidestarch graft copolymer, polymethylacrylate-starch graft copolymer, graft polymerization of starch with acrylic, methacrylic acid, polymethylacrylatepregelled starch graft copolymer, or reacting of maize starch and hydrolyzed maize starch with the prepared citric acid adduct (2-hydroxy,3-chloropropyl citric acid $)^{(20)}$. Starch sulfates ${ }^{(4)}$, starch phosphates and starch carbamates have been studied as flocculants ${ }^{(21)}$.

Of particular concern are the starch phosphates. They are attractive candidates since they are fairly easy to prepare and the cost of the reactant sodium phosphate is low. They were shown to be helpful in the sedimentation of red mud in the Bayer process and in the precipitation of iron oxide. Concentrations of starch phosphate used were quite high $(0.6 \%)$ as were phosphorus levels $(0.5-5.0 \%)$. Wheat starch phosphate $(0.6 \% \mathrm{P})$ was found to be an effective flocculant for coal tailings at $4-10 \mathrm{ppm}^{(22)}$. Meiczinger et al. ${ }^{(21)}$ showed that waxy corn starch phosphates were effective flocculants for kaolin in water but the DS (degree of substitution) values were not determined and concentrations of starch phosphates required were not given ${ }^{(21)}$. Furthermore, none of these published studies have compared the effectiveness of starch phosphates with a good industrial flocculant such as PAM except Shogren ${ }^{(22)}$. Obviously, then, the effect of molecular weight on the ability of starch phosphates to flocculate was not explicitly studied. Little is known about the detailed effects of DS, molecular weight, concentration of divalent cations on the effectiveness of starch phosphates as flocculants.

The current study is undertaken with a view to synthesize starch hydroxypropyl phosphates having different degree of substitutions through synthesize modulating the catalyst concentration, the acid adduct concentration, duration and temperature using the dry state method. These obtained starch derivatives are evaluated as flocculants and flocculation efficiency of these flocculants is investigated under a variety of conditions. Factors studied include dose, phosphorus content (as indication of DS), $\mathrm{pH}$ of the flocculation medium and molar mass (as indication of molecular weight). The flocculation process is carried out using ferric laurate and kaolin solutions. Results obtained are compared with those obtained with known industrial flocculant, namely, poly(acrylamide-co-acrylic acid). This is done to clarify the commercial potential of the so prepared starch hydroxypropyl phosphate flocculants.

Egypt. J. Chem. 56, No.5,6 (2013) 


\section{Experimental}

Materials

Lauric acid, sodium hydroxide, ferric chloride, epichlorohydrin and mono sodium salt of phosphoric acid were of analytical grade chemicals. Kaolin and poly(acrylamide-co-acrylic acid) wt $\%, \mathrm{M}_{\mathrm{w}}$ 5,000,000) were purchased from Aldrich Chemical (Germeny).

Maize starch was supplied by Cairo Company for Starch and Glucose (Cairo, Egypt). Three types of hydrolyzed starches namely $\mathrm{H}_{1^{-}}, \mathrm{H}_{2}$ - and $\mathrm{H}_{3}$-starches were prepared by $\mathrm{HCl}$ treatment of starch at $50^{\circ} \mathrm{C}$ for $2 \mathrm{hr}$ using a liquor ratio of 5 . The acid concentrations were $0.5,0.75$ and $1 \mathrm{~N}$ for preparation of $\mathrm{H}_{1^{-}}, \mathrm{H}_{2^{-}}$and $\mathrm{H}_{3}$ starch, respectively. $\mathrm{H}_{1^{-}}, \mathrm{H}_{2}$-and $\mathrm{H}_{3}$-starches acquire intrinsic viscosity $\eta$ values of 1.6, 0.8 and 0.6 (mPa.s), respectively. Starch and hydrolyzed starches have been used in further chemical modification to produce different starch phosphates.

The phosphate adduct, namely, 2-Hydroxy-3-chloropropyl phosphate was prepared by reacting of 1 mole epichlorohydrin with 0.9 mole of mono sodium salt of phosphate, under reflux until the formation of one phase. After partial cooling to $60-70^{\circ} \mathrm{C}$, the reaction product was poured into a large excess of $96 \%$ ethanol in a vessel to wash and remove the unreacted epichlorohydrin or glycols. The prepared compound was then filtered and dried ${ }^{(4)}$.

\section{Synthesis of starch hydroxypropyl phosphates}

The starch hydroxypropyl phosphates were prepared by reacting starch with 2hydroxy-3-chloropropyl phosphate (phosphate adduct), in presence of sodium hydroxide using the dry state technique according to a reported method ${ }^{(4)}$. Native and hydrolyzed starches were thoroughly mixed with powdered sodium hydroxide with different molar ratio according to phosphate adduct molar ratio) for $5 \mathrm{~min}$ using mechanical stirrer. The phosphate adduct ( $\mathrm{X}$ mol: anhydroglucose unit) was added to the starch/ $\mathrm{NaOH}$ mixture at room temperature and the letter was further subjected to thorough mixing for $5 \mathrm{~min}$ then transferred to a stoppered bottle which was kept in thermostatic water bath at different temperatures for different durations. At the end of reaction time the reaction product was poured onto $200 \mathrm{ml}$ ethanol and the $\mathrm{pH}$ was adjusted to 8 , filtered, soxhlet extracted for $12 \mathrm{hr}$ using ethanol : water mixture (80:20 v/v) and finally dried.

\section{Preparation of flocculant's solution}

The flocculant solution was prepared by cooking the starch phosphate $(1 \mathrm{~g})$ in distilled water $(90 \mathrm{ml})$ at $100^{\circ} \mathrm{C}$ up to complete solubility and clearance. After complete solubility the total volume of the solution was adjusted to $100 \mathrm{ml}$ with distilled water ${ }^{(4)}$. 
Preparation of ferric laurate

Lauric acid $(5 \mathrm{~g})$ was suspended in distilled water $(500 \mathrm{ml})$ in $1 \mathrm{~L}$ beaker, stirred at $60-70{ }^{\circ} \mathrm{C}$ and aqueous solution of sodium hydroxide $(10 \%)$ was added dropewise to the acid up to $\mathrm{pH}$ 10.5. Stirring was continued till the fatty acid salt dissolved completely. To this solution aqueous ferric chloride (10\%) was added dropewise to yield ferric laurate solution. The $\mathrm{pH}$ of the ferric laurate solution was adjusted to 6 and 8 by controlling the addition of ferric chloride solution. The suspension was then transferred to a one liter measuring flask and $30 \mathrm{ml}$ of ferric laurate solution were diluted to $1 \mathrm{~L}^{(4)}$.

\section{Preparation of kaolin}

Kaolin $(1 \mathrm{~g})$ and distilled water $(100 \mathrm{ml})$ were mixed at high speed in a $150 \mathrm{ml}$ beaker using a $2.5 \mathrm{~cm}$ long magnetic stir bar for $5 \mathrm{~min}^{(15)}$.

\section{Flocculation process}

Flocculation process for ferric laurate

The flocculant solution was added in different doses to a series of $250 \mathrm{ml}$ beakers containing $100 \mathrm{ml}$ of ferric laurate solution and the mixtures were mechanically stirred at $200 \mathrm{rpm}$ for $30 \mathrm{sec}$. After $10 \mathrm{~min}$ the solution was filtered ${ }^{(4)}$.

\section{Flocculation process for kaolin}

Flocculant solution was added to a $100 \mathrm{ml}$ of suspended kaolin and allowed to mix at high speed $(300 \mathrm{rpm})$ for $2 \mathrm{~min}$. Stirring speed was then reduced to $180 \mathrm{rpm}$ (just enough to keep kaolin in suspension) for $5 \mathrm{~min}$. The flocs were then allowed to settle for 2 min without stirring.

The transmission $\%$ of the filtrate of ferric laurate or aliquots taken at half height of the liquid column of kaolin were estimated using the spectronic $20 \mathrm{D}^{+}$ apparatus and the dry weight removal\% of the precipitate was estimated.

$$
\text { Weight Removal } \%=\frac{\text { Weight of precipitate }}{\text { The solid content of } 100 \mathrm{ml} \text { solution }} \quad X 100
$$

Degree of substitution (DS) and the reaction efficiency percent (RF\%) were calculated according to the following equations.

$$
\begin{aligned}
& \mathrm{DS}=\frac{\text { number of phosphorus moles } \mathrm{X} \text { phosphorus } \%}{100-(\text { number of phosphorus moles } \mathrm{X} \text { phosphorus \% })} \\
& \mathrm{RE} \%=\frac{\mathrm{DS} \times 100}{\text { theoretical phosphorus molar ratio }}
\end{aligned}
$$


W/MW of phosphate adduct X100

where theoretical phosphorus molar ratio $=$

W/MW of unhydro glucose unite

Testing and analysis

- The phosphorus content was determined according to reported methods ${ }^{(23)}$.

- The chlorine content was determined according to a reported method ${ }^{(24)}$.

\section{Results and Discussion}

Synthesis of starch hydroxypropyl phosphate

In an aqueous system containing starch, the 2-hydroxy-3-propyl phosphate and $\mathrm{NaOH}$, several reactions take place as suggested by Equations 1- 4 .<smiles>O=[P+]=NO</smiles>

$\mathrm{OH}$

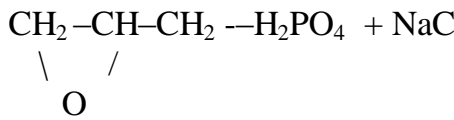
$\mathrm{OH}$

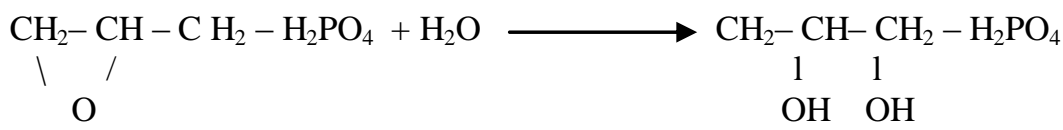

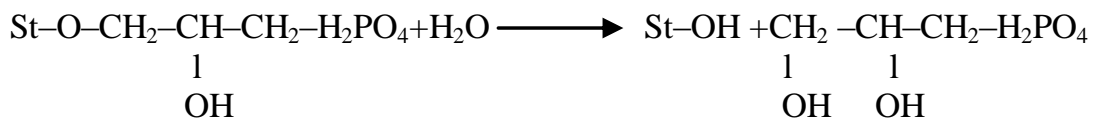

In Equation 1, the phosphate adduct is contested under the influence of $\mathrm{NaOH}$ to yield the reactive epoxy form of the adduct which, reacts with starch to bring about starch phosphate as showed the reaction suggested by Equation 2 . Equations 3 and 4 represent reactions of the reactive epoxy phosphate adduct with water as well as the splitting off the phosphate adduct grouping from starch phosphate in the alkaline medium of the reaction system. Both reactions suggested by Equations 3 and 4 adversely affect formation of starch phosphate.

With the above in mind, research was designed to study factors affecting formation of starch phosphate, notably, concentrations of sodium hydroxide and phosphate adduct in addition to temperature and duration of the etherification reaction. Results obtained are discussed below. 
Sodium hydroxide concentration

Figure 1 shows the dependence of the extent of the reaction of starch with phosphate adduct (expressed as phosphorus content) on the $\mathrm{NaOH}$ concentration. The reaction was carried out at $80^{\circ} \mathrm{C}$ for $180 \mathrm{~min}$. Using starch $(25 \mathrm{~m} \mathrm{~mole})$, phosphate adduct : starch molar ratio $0.5: 1$, and different sodium hydroxide : phosphate adduct molar ratio ( $3.13-25 \mathrm{~m}$ mole).

It is seen (Fig.1) that increasing $\mathrm{NaOH}$ concentration up to 15.63 molar ratio causes significant enhancement in the extent of the reaction. Thereafter, further increase in the alkali concentration causes a decrease. That is, the reaction exhibits its maximum at 15.63 molar ratio $\mathrm{NaOH}$. It is logical that lower $\mathrm{NaOH}$ concentrations are not sufficient enough to drive the reaction to its maximum, meanwhile higher $\mathrm{NaOH}$ concentration act in favor of alkaline hydrolysis of the functional group of phosphate adduct and/or splitting off of the phosphate adduct moieties from the starch via alkaline hydrolysis of the chemical bond linking the starch molecules with these moieties. Thus, it can be concluded that $\mathrm{NaOH}$ concentrations determine the magnitudes of the desirable reactions (Equations 1 and 2) and the side undesirable reactions (Equations 3 and 4) as well.

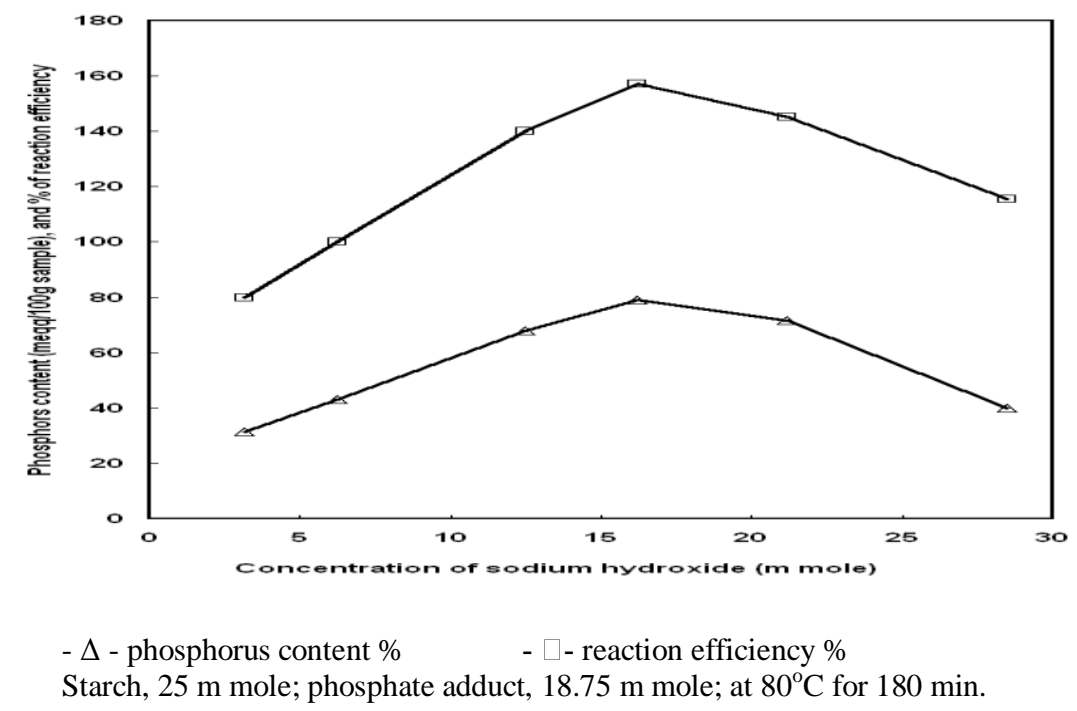

Fig.1.Effect of sodium hydroxide concentration on the magnitude of reaction of starch with phosphate adduct expressed as phosphorus content and reaction efficiency.

Phosphate adduct concentration

Figure 2 shows the phosphorus content, a measure for the extent of the reaction, as a function of phosphate adduct concentration when the latter was reacted at different phosphate adduct : starch molar ratios $(0.125-1.0)$ with starch $(25 \mathrm{~m} \mathrm{~mole})$, in presence of sodium hydroxide : phosphate adduct molar

Egypt. J. Chem. 56, No.5,6 (2013) 
ratio $1.25: 1$ at $80^{\circ} \mathrm{C}$ for $240 \mathrm{~min}$. Obviously, the extent of the reaction increases sharply as the phosphate adduct : starch molar ratio increases upto 0.75 molar ratio, then such increase becomes smaller even after phosphate adduct : starch molar ratio as high as 1.0 was used. This could be interpreted in terms of the solid state reaction condition limits the mobility of the phosphate adduct so that only starch and phosphate adduct molecules close to each other will react. Thus, a smaller proportion of the phosphate adduct will react as more is added. It is also possible that the amount of phosphate adduct which can diffuse into the starch granule is limited by the semi-crystalline structure and rigidity of starch granules ${ }^{(22)}$. It is rather possible that the phosphate adduct at higher concentrations are more susceptible to alkaline hydrolysis ${ }^{(20)}$. All such possibilities would counterbalance the sharp increase observed upon using phosphate adduct at concentrations upto 0.75 molar ratio.

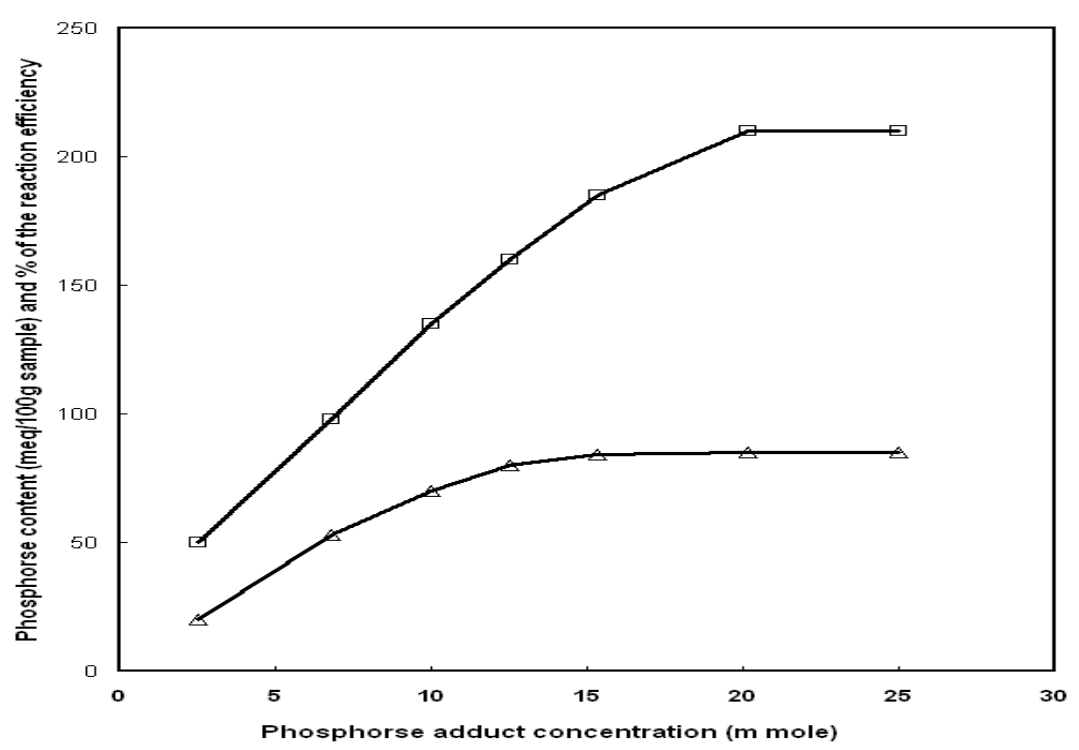

- $\Delta$ - phosphorus content $\% \quad$ - $\square$ - reaction efficiency $\%$

Starch, $25 \mathrm{~m}$ mole; sodium hydroxide: phosphate adduct concentration, 1.25:1 molar ratio; at $80^{\circ} \mathrm{C}$ for $240 \mathrm{~min}$.

Fig.2. Effect of phosphate adduct concentration on the magnitude of reaction of starch with phosphate adduct.

\section{Reaction temperature and durations}

Table 1 shows the effect of temperature and duration on the extent of the reaction occurring between starch and phosphate adduct in presence of $\mathrm{NaOH}$. The starch $(25 \mathrm{~m}$ mole) was reacted with phosphate adduct $(18.75, \mathrm{~m}$ mole) at different temperatures $\left(60-90{ }^{\circ} \mathrm{C}\right)$ and for varying lengths of durations (30-300 min). The reaction was affected under the influence of sodium hydroxide $(23.43 \mathrm{~m}$ mole $)$.

Egypt. J. Chem. 56, No.5,6 (2013) 
A close examination of Table 1 would reveal the following findings:

(1) The phosphorus content, degree of substitution (DS) and the reaction efficiency percent (RE\%) increase by raising the reaction temperature.

(2) Enhancement in the phosphorus content, degree of substitution and reaction efficiency percent depend on the reaction duration. For a given temperature the phosphorus content, degree of substitution and the reaction efficiency percent increase by prolonging the duration till maximum values are attained then decrease thereafter.

(3) Maximum values of the phosphorus content, degree of substitution and the reaction efficiency percent depend upon the temperature; these values amount to $(127,0.29,58 \%),(136.4,0.32,64 \%),(208,0.5,100 \%)$ at temperatures 60,70 , and $80{ }^{\circ} \mathrm{C}$, respectively.

(4) The maximum value of the phosphorus content, degree of substitution and reaction efficiency percent are obtained at $240 \mathrm{~min}$ with respect to all samples at different temperatures except at $90^{\circ} \mathrm{C}$ they are achieved at $60 \mathrm{~min}$.

(5) The phosphorus content, degree of substitution and reaction efficiency percent display the highest values which are equal to 208 meq. / $100 \mathrm{~g}$ sample, 0.5 and $100 \%$, respectively; such values could be arrived at $80{ }^{\circ} \mathrm{C}$ and $240 \mathrm{~min}$.

TABLE 1. Effect of temperature and duration on the phosphorus content, degree of substitution (D.S.) and percent of reaction efficiency (R.E.\%).

\begin{tabular}{|c|c|c|c|c|c|c|c|c|c|c|c|c|}
\hline $\begin{array}{c}\text { Tempe } \\
\text {-rature } \\
{ }^{\circ} \mathrm{C}\end{array}$ & \multicolumn{3}{|c|}{$60^{\circ} \mathrm{C}$} & \multicolumn{3}{|c|}{$7^{\circ} \mathrm{C}$} & \multicolumn{3}{|c|}{$80^{\circ} \mathrm{C}$} & \multicolumn{3}{|c|}{$90^{\circ} \mathrm{C}$} \\
\hline \begin{tabular}{|c}
${ }^{\circ} \mathbf{C}$ \\
Durat- \\
ion \\
min
\end{tabular} & \begin{tabular}{|c} 
Phos- \\
phorus \\
content \\
(meq/ \\
100g \\
sample)
\end{tabular} & D.S. & $\underset{\%}{\text { R.E. }}$ & 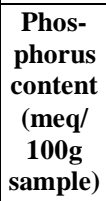 & D.S & $\underset{\%}{\text { R.E. }}$ & 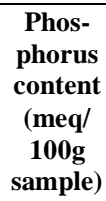 & D.S. & $\underset{\%}{\text { R.E. }}$ & 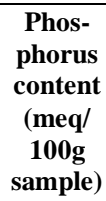 & D.S. & $\underset{\%}{\text { R.E. }}$ \\
\hline 30 & 52.7 & 0.1 & 20 & 68.2 & 0.13 & 26 & 83.7 & 0.17 & 33.5 & 99.2 & 0.21 & 42 \\
\hline 60 & 71.3 & 0.14 & 28 & 86.8 & 0.18 & 36 & 99.2 & 0.21 & 42 & 130.2 & 0.30 & 60 \\
\hline 120 & 99.2 & 0.21 & 42 & 111.6 & 0.25 & 50 & 158 & 0.39 & 78 & 71.3 & 0.14 & 28 \\
\hline 180 & 117.8 & 0.26 & 52 & 130.2 & 0.30 & 60 & 164 & 0.42 & 84 & 40.3 & 0.07 & 14 \\
\hline 240 & 127 & 0.29 & 58 & 136.4 & 0.32 & 64 & 208 & 0.5 & 100 & 37.2 & 0.06 & 12 \\
\hline 300 & 127 & 0.29 & 58 & 133.3 & 0.31 & 62 & 145.7 & 0.35 & 70 & - & - & - \\
\hline
\end{tabular}

Starch, $25 \mathrm{~m}$ mole; phosphate adduct, $18.75 \mathrm{~m}$ mole; sodium hydroxide, $23.43 \mathrm{~m}$ mole.

Evaluation of starch hydroxypropyl phosphate as flocculant for ferric laurate and kaolin

Flocculant dose for ferric laurate

Flocculation of ferric laurate was carried out using the starch hydroxypropyl phosphate in question at various doses $(\mathrm{ppm})$. This starch derivative acquires phosphorus content of $208 \mathrm{~m}$ eq /100 g sample. Figure 3 shows the effect of flocculant dose on the transmission $\%$ and weight removal $\%$ of the filtrate after flocculation of ferric laurate at $\mathrm{pH} 6$ and $\mathrm{pH} 8$. 
It is seen (Fig. 3) that: the transmission\% and weight removal\% increase with increasing the flocculant dose to reach a maximum value and then decreases. This phenomenon has been observed by several authors ${ }^{(4,16,20)}$; the flocculant dose that gives rise to maximum transmission $\%$ and weight removal\% value is considered as optimal dose value. It is also seen that this phenomenon occurs at $\mathrm{pH} 6$ and $\mathrm{pH} 8$.

The formation of optimal dose value may be explained as follows:

It is known that ferric laurate suspension has anionic demand of 2 and 1.6 for samples prepared at $\mathrm{pH} 6$ and $\mathrm{pH} 8$, respectively ${ }^{(25)}$. Addition of starch hydroxypropyl phosphate to the ferric laurate suspension leads to attraction between the suspended particles bearing positive charge and the acidic groups of starch hydroxypropyl phosphate. The starch derivative molecules attached to solid particles still have free active centers that can be adsorbed on the remaining free surface of other particles. This process results in "bridging" between solid particles and in the consequent formation of large flocs having a three-dimensional network structure. Beside bridging, the addition of the flocculant charge neutralization increases to reach zeta potential value of zero at which maximum flocculation $\operatorname{occurs}^{(4,16,20)}$. This occurs at the optimal dose value. After this situation, higher flocculant doses may impart an electric negative charge to suspended particles high enough to cause mutual repulsion. In addition, at higher doses the polymer covers most of the observed sites on each particle and bridging becomes negligible. The overall result is redispersal of the flocs because of the electrostatic repulsion.

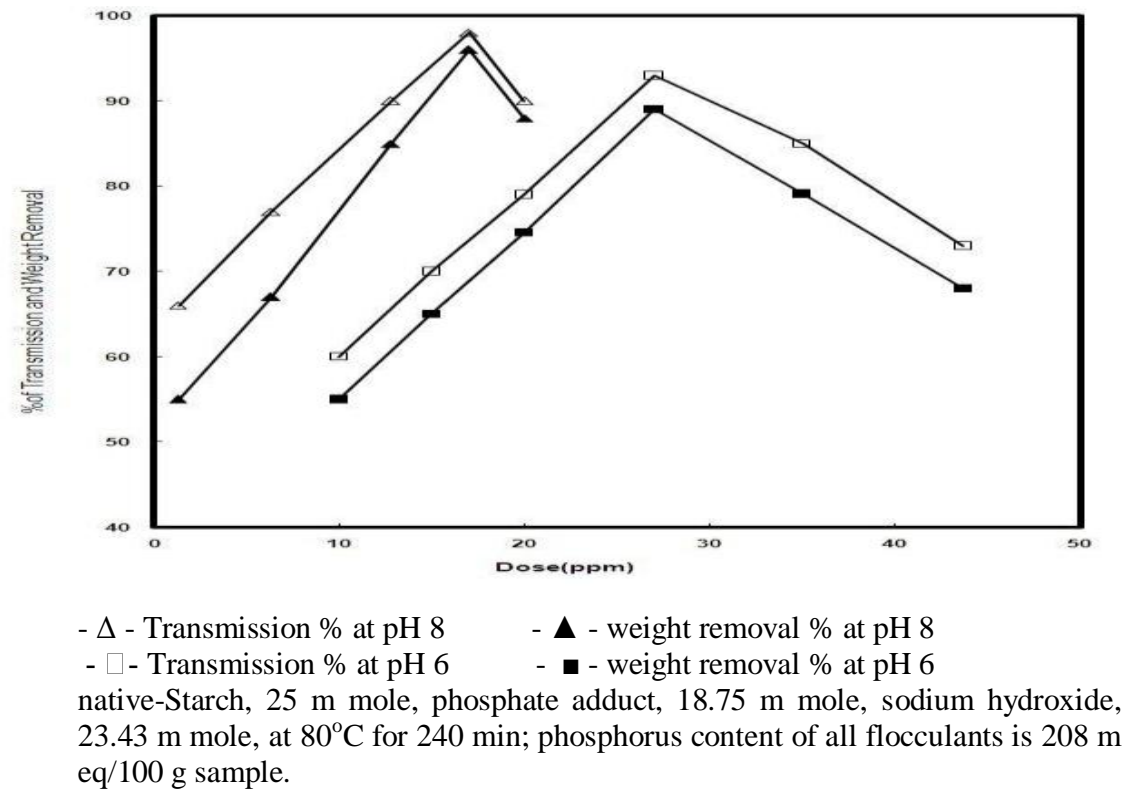

Fig. 3. Effect of dose on the transmission \% and weight removal \% in case of ferric laurate.

Egypt. J. Chem. 56, No.5,6 (2013) 
Flocculant dose for kaolin

Figure 4 shows the extent of flocculation of kaolin in water by starch hydroxypropyl phosphate at $\mathrm{pH} 6.0$ and $\mathrm{pH} 8$. Flocculation was carried out using various doses (ppm) of starch hydroxypropyl phosphate. The latter acquires phosphorus content of $208 \mathrm{~m}$ eq /100 g sample. Evidently, the two methods used to characterize the amount of kaolin left in suspension after settling, transmission \% and weight removal $\%$ of the filtrate after flocculation, gave similar trends. As dose increases, transmission $\%$ and weight removal $\%$ of the filtrate after flocculation increase to reach maximum values and then actually decrease with increasing starch hydroxypropyl phosphate dose, indicating that higher doses of starch hydroxypropyl phosphate act as suspending agents rather than flocculants.

The behavior noted above can be interpreted in terms of solubility and charge densities of starch hydroxypropyl phosphate and kaolin. Starch hydroxypropyl phosphate, is more highly anionic and water soluble, thus the free energy of absorption to a solid substrate would be less favorable. Since kaolin $\left(\mathrm{Al}_{2} \mathrm{O}_{3} 2 \mathrm{SiO}_{2} 2 \mathrm{H}_{2} \mathrm{O}\right)$ has a net negative charge at neutral $\mathrm{pH}$, negatively charged starch hydroxypropyl phosphate would not tend to interact strongly with kaolin. Instead, starch phosphate molecules would tend to surround the kaolin particles and prevent them from agglomerating into larger particles and flocculating ${ }^{(22)}$.

As shown in Fig. 3 and 4 the transmission $\%$ and weight removal $\%$ were $70 \%$ and $62 \%$, respectively in case of kaolin where they were reaching $98 \%$, and $96 \%$ in case of ferric laurate.

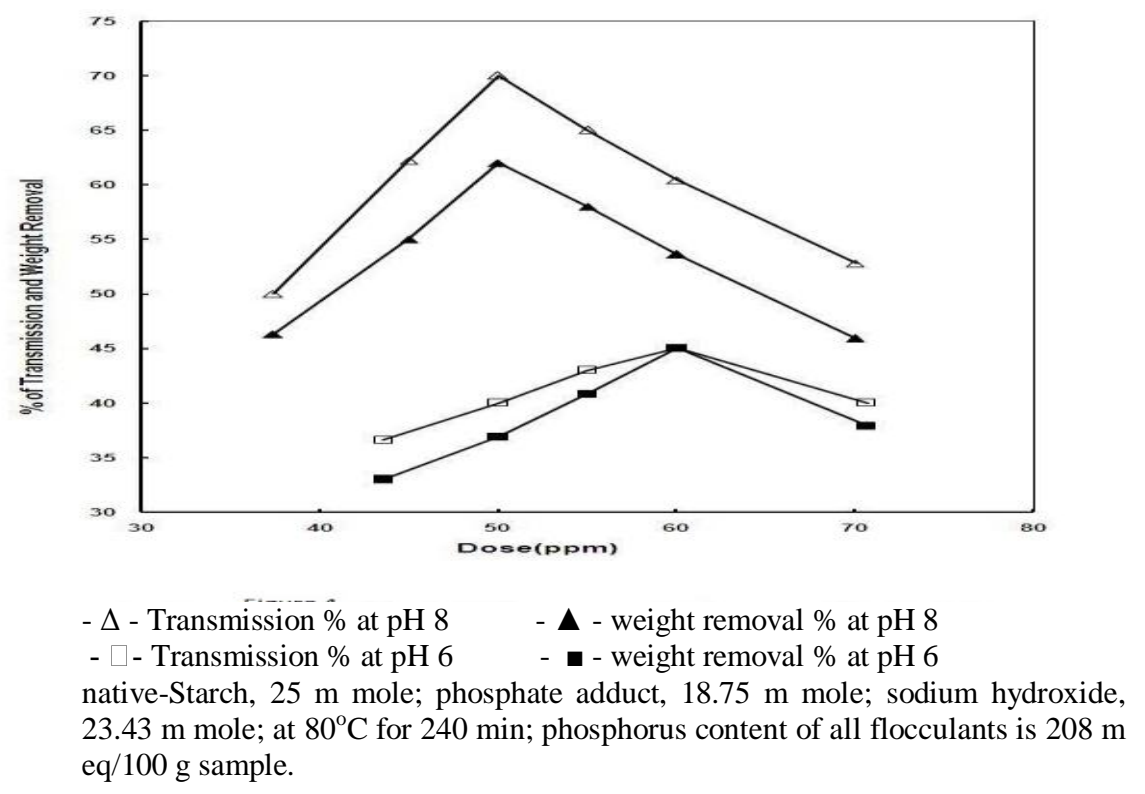

Fig. 4. Effect of dose on the transmission\% and weight removal \% in case of kaolin.

Egypt. J. Chem. 56, No.5,6 (2013) 


\section{pH of flocculation}

Flocculation of ferric laurate and kaolin suspensions at $\mathrm{pH} 6$ and $\mathrm{pH} 8$ was affected using starch hydroxypropyl phosphate having (phosphorus content of $208 \mathrm{~m} \mathrm{eq} / 100 \mathrm{~g}$ sample). Table 2 shows the transmission\% and weight removal\% of flocculated samples at the optimal flocculant doses.

The results (Table 2) make it evident that the optimal dose value depends on the $\mathrm{pH}$ of flocculation medium; the optimal dose at $\mathrm{pH} 6$ is greater than at $\mathrm{pH} 8$. Reasons for this may be cited as follows: (a) the anionic demand of ferric laurate is higher at $\mathrm{pH} 6$ than that at $\mathrm{pH} 8$, meanwhile kaolin has a net negative charge at neutral $\mathrm{pH}$, (b) The degree of ionization of weak acids in the sodium form is higher than the hydrogen form and (c) The molar extension of anionic flocculants at $\mathrm{pH} 8$ is higher than at $\mathrm{pH} 6$ ( $c f$. Table 3). It is also evident that the transmission\% and the weight removal \%, obtained when the optimal flocculant doses were used, depend on the $\mathrm{pH}$ and they display higher values at $\mathrm{pH} 8$ than at $\mathrm{pH} 6$.

The flocculation process at $\mathrm{pH} 8$ consumes lower flocculant dose than at $\mathrm{pH} 6$ thereby giving rise to higher transmission $\%$ and weight removal $\%$ values. This means that the flocculation efficiency of anionic flocculant is higher at $\mathrm{pH} 8$ than $\mathrm{pH}$ 6. It is as well to emphasize that ferric laurate suspension undergoes better flocculation than the kaolin suspension.

TABLE 2. The effect of $\mathrm{pH}$ of ferric laurate and kaolin solutions on the transmission $\%$ and weight removal \% obtained using starch phosphate at optimal flocculant dose (ppm).

\begin{tabular}{|c|c|c|c|c|c|c|}
\hline $\begin{array}{c}\text { Type of } \\
\text { suspended } \\
\text { solution }\end{array}$ & \multicolumn{2}{|c|}{$\begin{array}{c}\text { Optimal dose } \\
\text { (ppm) }\end{array}$} & \multicolumn{2}{c|}{ Weight removal \% } & \multicolumn{2}{c|}{ Transmission \% } \\
\cline { 2 - 7 } & pH 8 & pH 6 & pH 8 & pH 6 & pH 8 & pH 6 \\
\hline Ferric laurate & 17 & 27 & 96 & 89 & 98 & 93 \\
\hline kaolin & 50 & 60 & 62 & 45 & 70 & 45 \\
\hline
\end{tabular}

phosphorus content of all flocculants is $208 \mathrm{~m} \mathrm{eq} / 100 \mathrm{~g}$ sample.

TABLE 3. The intrinsic viscosity of flocculants at pH 6 and pH 8.

\begin{tabular}{|c|c|}
\hline $\mathbf{p H}$ & $\mathbf{I}$ \\
\hline 6 & 0.80 \\
\hline 8 & 1.25 \\
\hline
\end{tabular}

Flocculant molar mass

Starches having different molecular masses, namely, native starch and three hydrolyzed starches prepared thereof $\left(\mathrm{H}_{1^{-}}, \mathrm{H}_{2}-\right.$ and $\mathrm{H}_{3}$-starch) were converted to the phosphate derivatives. Formation of the phosphate was dealt with in as such that all these starch hydroxypropyl phosphate acquire phosphorus content of $208 \mathrm{~m}$ eq /100 g sample. These starch hydroxypropyl phosphates we used as 
flocculants for flocculation of ferric laurate and kaolin. Table 4 shows the transmission $\%$ and weight removal\% at the optimal dose of different samples.

Results set out in Table 4 highlight several findings which can be summarized : (i) the optimal dose values decrease with decreasing the molar mass of the flocculant and follow the order: native starch $>\mathrm{H}_{1}$-starch $>\mathrm{H}_{2}$-starch $>\mathrm{H}_{3}$ starch; (ii) the transmission\% and weight removal\% decrease by decreasing the molar mass of the flocculant; (iii) flocculation using flocculant based on native starch exhibits the highest flocculant dose, transmission\% and weight removal\%, while that based on $\mathrm{H}_{3}$-starch displays the lowest flocculant dose, transmission\% and weight removal\%, while those based on $\mathrm{H}_{1}$-starch and $\mathrm{H}_{2}$-starch lie in between and; (iv) the concerns of i, ii, and iii pertaining to ferric laurate are also holding true for kaolin.

The behavior reported above can be rationalized in terms of solubility and charge densities of starch hydroxypropyl phosphate, ferric laurate and kaolin. Starch hydroxypropyl phosphates are more highly anionic and water soluble and thus the free energy of absorption to a solid substrate would be less favorable ${ }^{(22)}$, in accordance with the results presented $\mathrm{pH}$ of flocculation.

TABLE 4. The effect of molar mass of different flocculants on the optimal dose (D in ppm ), weight removal \% (W) and transmission \% (T) at pH 8.

\begin{tabular}{|c|c|c|c|c|c|c|}
\hline \multirow{2}{*}{ Type of starch } & \multicolumn{3}{|c|}{ ferric laurate } & \multicolumn{3}{c|}{ kaolin } \\
\cline { 2 - 7 } & D & W & T & D & W & T \\
\hline Native starch & 17 & 96 & 98 & 50 & 62 & 70 \\
\hline $\mathrm{H}_{1}$-starch & 14 & 86 & 90 & 45 & 51 & 55 \\
\hline $\mathrm{H}_{2}$-starch & 9 & 77 & 81 & 30 & 48 & 50 \\
\hline $\mathrm{H}_{3}$-starch & 4 & 74 & 78 & 10 & 45 & 45 \\
\hline
\end{tabular}

phosphorus content is $208 \mathrm{~m}$ eq $/ 100 \mathrm{~g}$ sample.

$\mathrm{H}_{1}-, \mathrm{H}_{2}$-and $\mathrm{H}_{3}$-starches acquire intrinsic viscosity $\eta$ values of $1.6,0.8$ and 0.6 (mPa.s) respectively.

\section{Phosphorus content}

Flocculations of ferric laurate and kaolin were carried out using starch hydroxypropyl phosphate flocculants having different phosphorus contents. These flocculants were synthesized using native starch and phosphate adduct and flocculation performed at $\mathrm{pH} 6$ and $\mathrm{pH} 8$. Table 5 shows the optimal dose, transmission $\%$ and weight removal\% obtained when these flocculants were used. The results signify that the optimal dose of flocculation decreases as the phosphorus content of the flocculant increases, being dependent upon the $\mathrm{pH}$ where value of the optimal dose at $\mathrm{pH} 6$ is higher than $\mathrm{pH} 8$ in case of ferric laurate solution. On the contrary, the optimal dose of flocculation increases as the phosphorus content of the flocculant increases, depending on the $\mathrm{pH}$ where value of the optimal dose at $\mathrm{pH} 6$ is higher than $\mathrm{pH} 8$ in case of kaolin solution. Meanwhile, the transmission\% of flocculated solution and the weight removal \% increase by increasing the flocculant phosphorus content ${ }^{(4)}$.

Egypt. J. Chem. 56, No.5,6 (2013) 
TABLE 5. The effect of phosphorus content $\mathrm{m}$ eq /100 $\mathrm{g}$ sample of various anionic flocculants based on native -starch on the optimal dose( $D$ in $p p m)$, transmission \% (T) and weight removal \% (W) of flocculated ferric laurate and kaolin at pH 8 and pH 6.

\begin{tabular}{|c|c|c|c|c|c|c|c|c|c|c|c|c|}
\hline \multirow{3}{*}{$\begin{array}{c}\text { Phosphorus } \\
\text { content }\end{array}$} & \multicolumn{6}{|c|}{ Ferric laurate } & \multicolumn{6}{|c|}{ Kaolin } \\
\hline & \multicolumn{3}{|c|}{ pH 8} & \multicolumn{3}{|c|}{$\mathrm{pH} 6$} & \multicolumn{3}{|c|}{ pH 8} & \multicolumn{3}{|c|}{ pH 6} \\
\hline & D & W & $\mathbf{T}$ & D & W & $\mathbf{T}$ & D & $\mathbf{W}$ & $\mathbf{T}$ & D & W & $T$ \\
\hline 60 & 39 & 67 & 71 & 72 & 59 & 67 & 10 & 18 & 22 & 15 & 15 & 20 \\
\hline 86 & 35 & 74 & 78 & 56 & 67 & 75 & 11 & 20 & 25 & 15 & 20 & 23 \\
\hline 99 & 31 & 80 & 84 & 44 & 73 & 81 & 13 & 22 & 27 & 20 & 20 & 25 \\
\hline 112 & 29 & 83 & 87 & 41 & 76 & 84 & 15 & 28 & 31 & 30 & 25 & 30 \\
\hline 130 & 26 & 86 & 90 & 38 & 79 & 87 & 17 & 35 & 38 & 35 & 30 & 33 \\
\hline 140 & 24 & 87 & 91 & 35 & 80 & 88 & 27 & 40 & 42 & 40 & 31 & 33 \\
\hline 158 & 22 & 88 & 92 & 33 & 81 & 89 & 38 & 45 & 49 & 45 & 35 & 33 \\
\hline 164 & 20 & 89 & 93 & 30 & 82 & 90 & 42 & 50 & 56 & 50 & 35 & 33 \\
\hline 195 & 19 & 90 & 93 & 29 & 83 & 91 & 48 & 55 & 65 & 55 & 35 & 35 \\
\hline 208 & 17 & 96 & 98 & 27 & 89 & 93 & 50 & 62 & 70 & 60 & 45 & 45 \\
\hline
\end{tabular}

Comparison between poly(acrylamide-co-acrylic acid) (PAM) and starch hydroxypropyl phosphate flocculants

Table 6 shows the flocculation effect of poly(acrylamide-co-acrylic acid) (PAM) on the kaolin and ferric laurate solutions. As evident, the transmission \% amounts to $98 \%$ at dose of 2.0 ppm PAM in case of kaolin. PAM is, therefore, an effective flocculant than starch hydroxypropyl phosphate flocculants under investigation in case of kaolin.

The reason that PAM is a more effective flocculant than starch hydroxypropyl phosphate flocculants could be associated with the linear backbone of PAM and random coil conformation which lead to a larger $R_{\mathrm{g}}$ for PAM than starch at similar molecular weights ${ }^{(26)}$. The more compact structure of highly branched amylopectin molecules decreases the extent of bridging contacts with kaolin particles and thus a higher doses of starch hydroxypropyl phosphate is needed for flocculation.

Table 6 discloses that the transmission \% equals to $74 \%$ at $4 \mathrm{ppm}$ of poly(acrylamide-co-acrylic acid) (PAM) in case of ferric laurate. The transmission \% is $98 \%$ at 17 pmm of starch hydroxypropyl phosphate as shown in Table 2. The ultimate effect of PAM flocculant is redispersal of the flocs because of electrostatic repulsion between the poly(acrylamide-co-acrylic acid) and ferric laurate where each of them has the same charge.

Even though starch hydroxypropyl phosphates are less effective flocculants than poly(acrylamide-co-acrylic acid), the cost of starch hydroxypropyl phosphates is much lower than poly(acrylamide-co-acrylic acid) thus making starch phosphate flocculants potentially economically competitive. Therefore, 
even higher concentration of starch hydroxypropyl phosphate is required, the cost may be comparable to or even less than poly(acrylamide-co-acrylic acid $)^{(2,22)}$. This in combination with the eco-friendly nature of the starch hydroxypropyl phosphate. Flocculants would advocate them as good candidates for flocculation.

TABLE 6. The effect of poly(acrylamide-co-acrylic acid) (PAM) value on ferric laurate and kaolin solutions as the transmission \%.

\begin{tabular}{|c|c|c|c|}
\hline \multicolumn{2}{|c|}{ Ferric laurate } & \multicolumn{2}{c|}{ Kaolin } \\
\hline Dose(ppm) & \% Transsimion & Dose(ppm) & \% Transsimion \\
\hline 0.5 & 25 & 0.3 & 30 \\
\hline 1.0 & 30 & 0.5 & 60 \\
\hline 1.5 & 32 & 1.0 & 80 \\
\hline 2.0 & 50 & 1.5 & 95 \\
\hline 2.5 & 60 & 2.0 & 98 \\
\hline 3.5 & 68 & 2.5 & 93 \\
\hline 4.0 & 74 & ---- & ---- \\
\hline 4.5 & 65 & --- & -- \\
\hline
\end{tabular}

\section{Conclusions}

Environment-friendly starch hydroxypropyl phosphate flocculants were synthesized under a variety of conditions including catalysts, phosphate adduct concentrations and molar mass of starch in addition to temperature and duration of the synthesis. The output of this was the most appropriate conditions for the synthesis of starch hydroxypropyl phosphate flocculants which comprise; phosphate adduct : starch molar ratio 0.75:1; sodium hydroxide : phosphate adduct molar ratio $1.25: 1$; temperature and time of the synthesis $80{ }^{\circ} \mathrm{C}$ for 240 min. Under these conditions starch hydroxypropyl phosphate floculant having phosphorus content of $208 \mathrm{~m}$ eq $/ 100 \mathrm{~g}$ sample) could be acheived. This flocculant was used successfully at also of $17 \mathrm{ppm}$ and $50 \mathrm{ppm}$ in flocculation of ferric laurate and kaolin, respectively, at $\mathrm{pH} 8$. Accordingly, the transmission\% was equal to $98 \%$ and weight removal\% equal to $96 \%$ of the filtrate after flocculation of ferric laurate. Against this were values of $70 \%$ and $62 \%$ in case of kaolin. In comparison study, starch hydroxypropyl phosphate flocculant was more effective than the conventional poly(acrylamide-co-acrylic acid) (PAM) flocculant upon use in flocculation of ferric laurate solution but it was much less effective upon use in flocculation of kaolin solution.

\section{References}

1. Bratby, J., Coagulation and Flocculation in Water and Wastewater Treatment, $\left(2^{\text {nd }}\right.$ ed.)IWA Publishing, London, p. 186-218 (2006).

2. Orts, W.J., Sojka, R.E. and Glenn, G.M., Biopolymer additives to reduce erosioninduced soil losses during irrigation. Industrial Crops and Products, 11, 19-29 (2000).

Egypt. J. Chem. 56, No.5,6 (2013) 
3. Sharma, B.R., Dhuldhoya, N.C. and Merchant, U.C., Flocculants: an ecofriendly approach. Journal of Polymers and the Environment, 14, 195-202 (2006).

4. Khalil, M.I. and Aly, A.A., Preparation and evaluation of some anionic starch derivatives as flocculants. Starch/Stärke 54, 132 - 139 (2002).

5. Deng, Y., Dixon, J.B. and Norman White, G., Adsorption of polyacrylamide on smectite, illite, and kaolinite. Soil Sci. Soc. Am. J. 70, 297-304 (2006).

6. Plank, J., Dugonjić-Bilić, F. and Lummer, N.R., Modification of the molar anionic charge density of acetone-formaldehyde-sulfite dispersant to improve adsorption behavior and effectiveness in the presence of CaAMP-co-NNDMA cement fluid loss polymer. J. of Applied Polymer Science 111(4), 2018-2024 (2009).

7. Cengiz, I., Sabah, E., Ozgen, S.H. and Akyildiz, Flocculation of fine particles in ceramic wastewater using new types of polymeric flocculants. J.Applied Polymer Science, 112 (3), 1258 - 1264 (2009).

8. Ersoy, B., Tosun, I., Günay, A. and Dikmen, S., Turbidity removal from wastewaters of natural stone processing by coagulation/flocculation methods. Clean - Soil, Air, Water, 37 (3), 225 - 232 (2009).

9. Liu, Y., Wang, S. and Hua, J., Synthesis of complex polymeric flocculants and its application in purifying water. J. Appl.Polym. Sci. 76, $2093-2097$ (2000).

10. Hammaker, J. and Mash, E., Synthesis and characterization of a poly(acrylamide) with pendant 1,4--piperazine-2,5-dione moieties via post-polymerization cyclization. J. Macromolecular Science, Part A: Pure and Applied Chemistry, 45 (10), 865-871 (2008).

11. Gabriela, C., Elena, M. and Maria-Daniela, S., Flocculation efficiency of poly (acrylamide-co-acrylic acid) obtained by electron beam irradiation. Journal of Materials, Article ID 297123, 7 (2013).

12. Aly, A.A., Fahmy, H.M., Samaha, S.H., Ibrahim, N.A. and Abo-Shosha, M.H., Preparation and characterization of carbamoylethylated guar gum and utilization in flocculating of ferric laurate suspension. $3^{\text {rd }}$ International Conference of Textile; ion, NRC, Cairo, Egypt, April 2-4 , 590-596 (2006).

13. Fahmy, H.M., Aly, A.A., El-Sayed, Z., Ibrahim, N.A. and Abo-Shosha, M.I., Flocculation of ferric laurate suspension using cationized pyrodextrins. Poly. Plastic Engineering and Technology , 45, 49-53 (2006).

14. Prasertsan, P., Dermlim, W., Doelle, H. and Kennedy, J.F., Screening, characterization and flocculating property of carbohydrate polymer from newly isolated enterobacter loaccloacae WD7. Carbohydrate Polymers, 66, 289-297 (2006).

15. Chenxin, X., Feng, Y., Weiping Cao, Yu Xi and Zhiyong LU, Novel biodegradable flocculating agents prepared by phosphate modification of konjac. Carbohydrate Polymers, 67 (4), 566-571 (2007). 
16. Khalil, M.I. and Aly, A.A., Preparation and evaluation of some cationic starch derivatives as flocculants. Starch/Stärke, 53, 84-89 (2001).

17. Krentz, D., Lohmann, C., Schwarz, S., Bratskaya, S., Liebert, T. and Laube , J., Properties and flocculation efficiency of highly cationized starch derivatives. Starch/Stärke, 58, 161-169 (2006).

18. Pal, S., Mal, D. and Singh, R.P., Cationic starch: an effective flocculating agent. Carbohydrate Polymers, 59, 417-423 (2005).

19. Zhao, Y. and Wen, J., Synthesis of carboxymethyl starch for water treatment. Shuichuli Jishu, 32, 76-77 (2006).

20. Aly, Amal, A., Preparation, characterization and evaluation of anionic starch derivatives as flocculants and for metal removal. Starch/Stärke , 58, 391- 400 (2006).

21. Meiczinger, M., Dencs, J., Marton, G. and Dencs, B., Investigation of reactions occurring at starch phosphorylation. Industrial Engineering Chemistry Research, 44, 9581-9585 (2005).

22. Shogren, R.L., Flocculation of kaolin by waxy maize starch phosphates. Carbohydrate Polymers, 76 (4), 639-644 (2009).

23. Vogel, A.I., “A Text-Book of Quantitative Inorganic Analysis Including Elementary Instrumental Analysis". $3^{\text {rd }}$., Longman Group Ltd., London, p. $402-404$ (1972).

24. Klimov, V.A, Basic Methods of Organic Microanalysis, Mir. Publishers. Moscow, chapter 5 (1975).

25. Cherian, X.M., Satymoorthy, P. and Kumar, V.N.G., Starch derivatives for flocculation of ferric soaps. Starch/Stärke, 44, 301-305 (1992).

26. Yoo, S. and Jane, J., Molecular weights and gyration radii of amylopectins determined by high-performance size-exclusion chromatography equipped with multiangle laser-light scattering and refractive index detectors. Carbohydrate Polymers, 49, 307-314 (2002). 


\section{تحضير وتقييم مادة مجمعة جديدة صديقة للبيئة هيدروكسي بروبيل

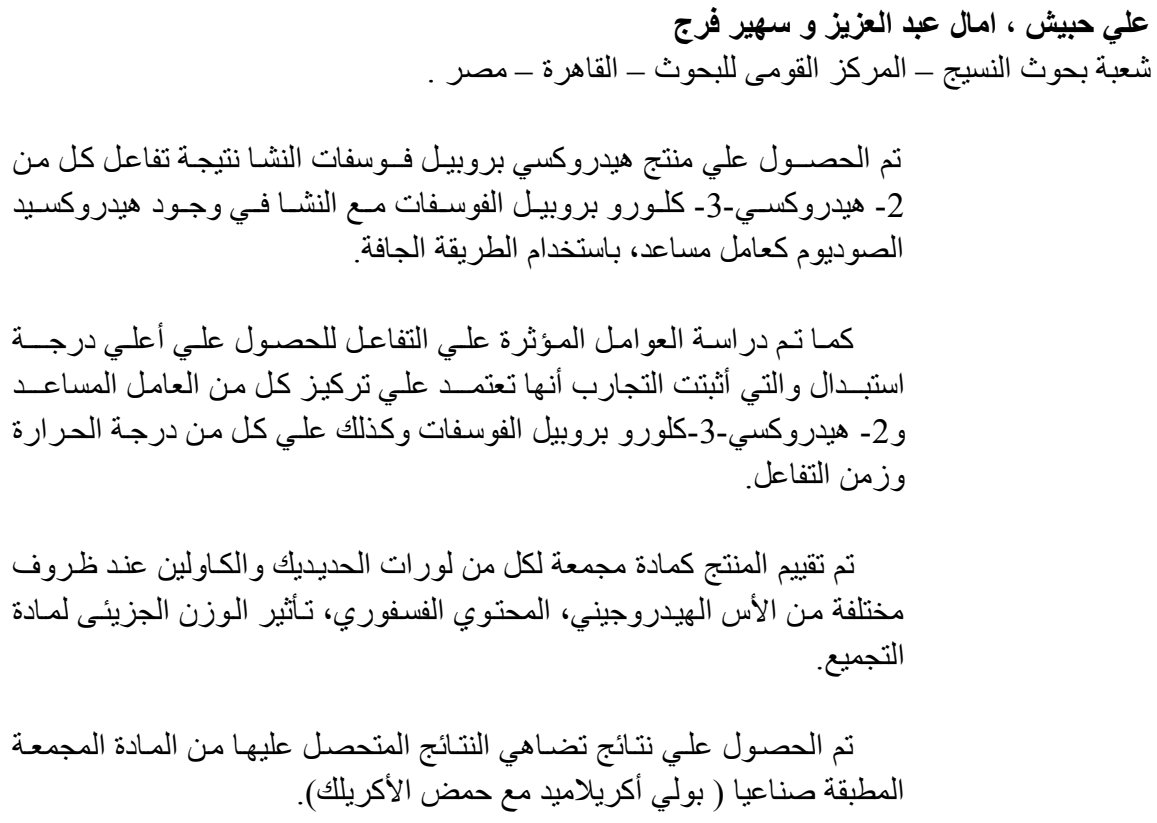

